\title{
BMJ Open Estimating the costs of the national basic public health services in Zhuhai, China, through activity-based costing: a cross-sectional study
}

Zan Wang, Qin Ao, Yinbo Luo, Qi Wang, Zuxun Lu, Jun'an Liu

To cite: Wang Z, Ao Q, Luo Y, et al. Estimating the costs of the national basic public health services in Zhuhai, China, through activity-based costing: a cross-sectional study. BMJ Open 2019;9:e024831. doi:10.1136/ bmjopen-2018-024831

- Prepublication history and additional material for this paper are available online. To view these files, please visit the journal online (http://dx.doi. org/10.1136/bmjopen-2018024831).

Received 26 June 2018

Revised 9 June 2019

Accepted 13 June 2019
Check for updates

(C) Author(s) (or their employer(s)) 2019. Re-use permitted under CC BY-NC. No commercial re-use. See rights and permissions. Published by BMJ.

School of Public Health, Tongji Medical College, Huazhong University of Science and Technology, Wuhan, China

Correspondence to

Dr Jun'an Liu;

lja10_11@163.com

\section{ABSTRACT}

Objective Our research aims to estimate the per capita cost of 13 items in the basic public health service (BPHS) project in Zhuhai, China, and provide an economical basis for the improvement of the cost compensation mechanism used by the government.

Design This research is a cross-sectional study.

Setting A total of 19 primary healthcare facilities (PHFs) in Zhuhai, China, are involved in this research.

Participants A total of 152 participants (114 personnel engaged in BPHS, 19 financial personnel and 19 PHF heads) were included in this study, which was conducted from May 2017 to July 2017.

Primary and secondary outcome measures We used the activity-based costing model to calculate the cost of providing BPHS in Zhuhai. An analytical hierarchy process was used to determine the difficulty dimension and workload coefficient.

Results The weights of the difficulty dimensions in the provision of BPHS in Zhuhai were $35.04 \%$ (coordination of residents), $24.03 \%$ (staff workload), $21.36 \%$ (complexity of work-related skills) and $19.59 \%$ (basic qualities of staff). The average difficulty coefficient of each subproject was 5.28. The actual per capita cost of BPHS provision in 2016 was 97.48 RMB (12.76 EUR), which was higher than the actual standard compensation of 55 RMB $(7.2$ EUR) in Zhuhai. Immunisation was the most costly among the 13 service items (17.82 RMB or 2.33 EUR per person), whereas the management of tuberculosis was the least costly item (0.57 RMB or 0.07 EUR per person).

Conclusions Government funds for basic public health services cannot compensate for the actual costs.

Accordingly, subsidies should be increased based on the actual per capita cost for sustainable BPHS development. The government should improve the methods used in cost estimation and measures used as the basis for awarding performance incentives.

\section{INTRODUCTION}

Basic public health services (BPHS) are essential healthcare services provided by the government to address the major health issues of its residents; the primary recipients of BPHS are children, pregnant women, elderly individuals and individuals with chronic

\section{Strengths and limitations of this study}

- This research calculates the cost of the provision of basic public health service (BPHS) in China using activity-based costing and considers the difficulty coefficient in BPHS provision.

- The survey involved personnel who are engaged in BPHS, financial personnel and primary healthcare facility (PHF) heads; the data gathered comprehensively reflect the basic situation and financial standing of the BPHS project.

- The geographical scope of our study was limited. Thus, the results may not be representative of other regions in China.

- This research involves a cross-sectional survey, and the results can reflect only the situation in 2016.

diseases. ${ }^{1}$ BPHS is a pure public good. Thus, the expenses incurred in providing healthcare services should be compensated by the government. The World Bank proposed the concept of BPHS in the World Development Report in 1993; generally, public health services can solve the health problems of a population, while a BPHS package should include cost-effective and efficient public health interventions. ${ }^{2}$ The USA and northern European countries considerably focus on BPHS development, and funds for this are directly allocated by the federal government to promote basic public health. Moreover, these countries actively explore a cost estimation method that can ensure the efficient provision of BPHS.

Costs are estimated on the basis of available knowledge, while effective methods and data are used to obtain information that can predict future costs. An ideal cost calculation is indispensable in the decision-making process. ${ }^{3}$ In 2016, Resnick used a coding framework to code US $\$ 1.9$ million, while the per capita cost of BPHS in the USA from 2013 to 2016 was US\$ 93. ${ }^{4}$ Leider assessed public 
health activity on the basis of national health expenditure accounts. ${ }^{5}$ Mays and Mamaril used a micro-costing methodology to estimate the costs of BPHS. ${ }^{6}$ The majority of the cost estimations adopt activity-based costing (ABC). Time-driven ABC (TDABC) is the name of the model in which activity-based costing is used to estimate the cost of a service project when the 'time factor' is incorporated. ${ }^{7}$ Mandigo used the TDABC model to improve the use of healthcare resources in Mirebalais, Haiti, and this approach has caught the attention of scholars. ${ }^{8}$

In 2009, the Chinese central government launched a national BPHS project that integrates traditional public health services to promote the equalisation of BPHS. ${ }^{9}$ BPHS projects have been widely implemented in community healthcare centres and township hospitals, thereby improving the health status of Chinese residents. ${ }^{10}$

A unified minimum cost reimbursement standard is implemented for BPHS projects in China. A total of 45 RMB (5.89 EUR) was allotted for each person in 2016 and was increased to $50 \mathrm{RMB}$ (6.54 EUR) in $2017 .{ }^{11}$ Costs vary substantially in different cities. On the one hand, the cost of national service products increases. Hence, the cost of BPHS also increases. In 2009, BPHS consisted of 10 service items $^{12}$; two items were added after 2 years ${ }^{13}$, and some new service items were integrated in $2016 .{ }^{14}$ For example, the per capita service cost for the community residents of Guangzhou was 37.2 RMB (4.87 EUR) per year in $2009,{ }^{15}$ but it increased by $73.8 \%$ to 64.67 RMB (8.46 EUR) in $2014 .{ }^{16}$ On the other hand, the cost of BPHS varies by region owing to the differences among the social and economical statuses of the regions. For example, the cost of services is high in economically developed cities. ${ }^{17}$ Finally, the actual cost of BPHS and government subsidies vary for each region. In 2010, the cost of BPHS in Beijing was 49.26 RMB (6.47 EUR) per capita. However, the government subsidy was 25 RMB (3.28 EUR), thereby reducing compensation by $24.26 \mathrm{RMB}$ (3.19 EUR). ${ }^{18}$

Given the lack of a scientific cost calculation method for BPHS, insufficient local government funding has led to low-quality BPHS and inadequate access for residents to healthcare services. Therefore, this study aimed to (1) calculate the per capita cost of BPHS in Zhuhai, China, by using the activity-based costing method and (2) provide an economical basis for the improvement of the cost compensation mechanism used by the government.

\section{MATERIALS AND METHODS Research site}

Zhuhai is located in southern China and is situated on the edge of the South China Sea. This city is one of the special economic zones and the second largest port city in China. In 2016, the permanent resident population of Zhuhai was 1.63 million, while the per capita disposable income was $40154.10 \mathrm{RMB}$ (5257.15 EUR). ${ }^{19}$ This city has 31 primary healthcare facilities (PHFs). A total of 19 PHFs in Zhuhai were surveyed in this study, including 13 community healthcare centres (CHCs) and six township hospitals. The current study covers 0.93 million individuals who comprise $56.61 \%$ of Zhuhai's total population. The total number of staff members in 19 PHFs in Zhuhai is 1701. A total of 263 staff members are engaged in BPHS, thereby accounting for $15.46 \%$ of the total.

\section{Research procedures}

This study used a multistage stratified sampling method. The three administrative districts of Zhuhai had six township hospitals that were included in this study, and $50 \%$ of CHCs are sampled. Zhuhai has 25 CHCs. The top 13 CHCs are selected as research sites on the basis of the population covered by each community. Among the 263 staff members engaged in BPHS, we chose only those with relatively extensive experience (ie, those who have been engaged in BPHS for over 5 years, those with college education or above and those with intermediate titles or above). A total of 114 qualified staff members were selected as respondents of this study.

This study has gone through three stages. In the first stage, a seminar on BPHS cost estimation was conducted by the Zhuhai Health Bureau while a plan to conduct a field survey was formulated. In the second stage, the field investigation team divided the investigators into three groups. In coordination with the district health bureau, the first group facilitated a survey among the staff members participating in BPHS in which the staff members were required to answer a questionnaire. The second group conducted a semi-structured interview with the PHF heads. The main contents of the interviews were as follows: the basic situation of the PHF, the status of the government subsidies to BPHS and relevant opinions on the difficulty dimension. The third group instructed the financial staff members to accomplish a financial questionnaire. All the respondents completed questionnaires under the guidance of the investigators. After completing the questionnaire, the investigator checked questionnaires. If missing data were found, the respondents needed to complete the questionnaire on the spot before they could leave. In the third stage, all the questionnaires were submitted to the district health bureaus for checking. Evident erroneous reports were corrected immediately by the research team. A total of 152 participants (ie, 114 personnel engaged in BPHS, 19 financial personnel and 19 PHF heads) were included in this study, which was conducted from May 2017 to July 2017.

\section{Key components of this study and data collection}

Figure 1 shows the key components of this study and the research methods.

1. The data obtained through field investigation in Zhuhai are as follows:

- Financial revenue and expenditure of 19 primary healthcare facilities.

- Staff allocation in 19 primary healthcare facilities.

- Number of work hours required in each subproject of BPHS, number of implementers, annual service quantity and difficulty coefficient. 


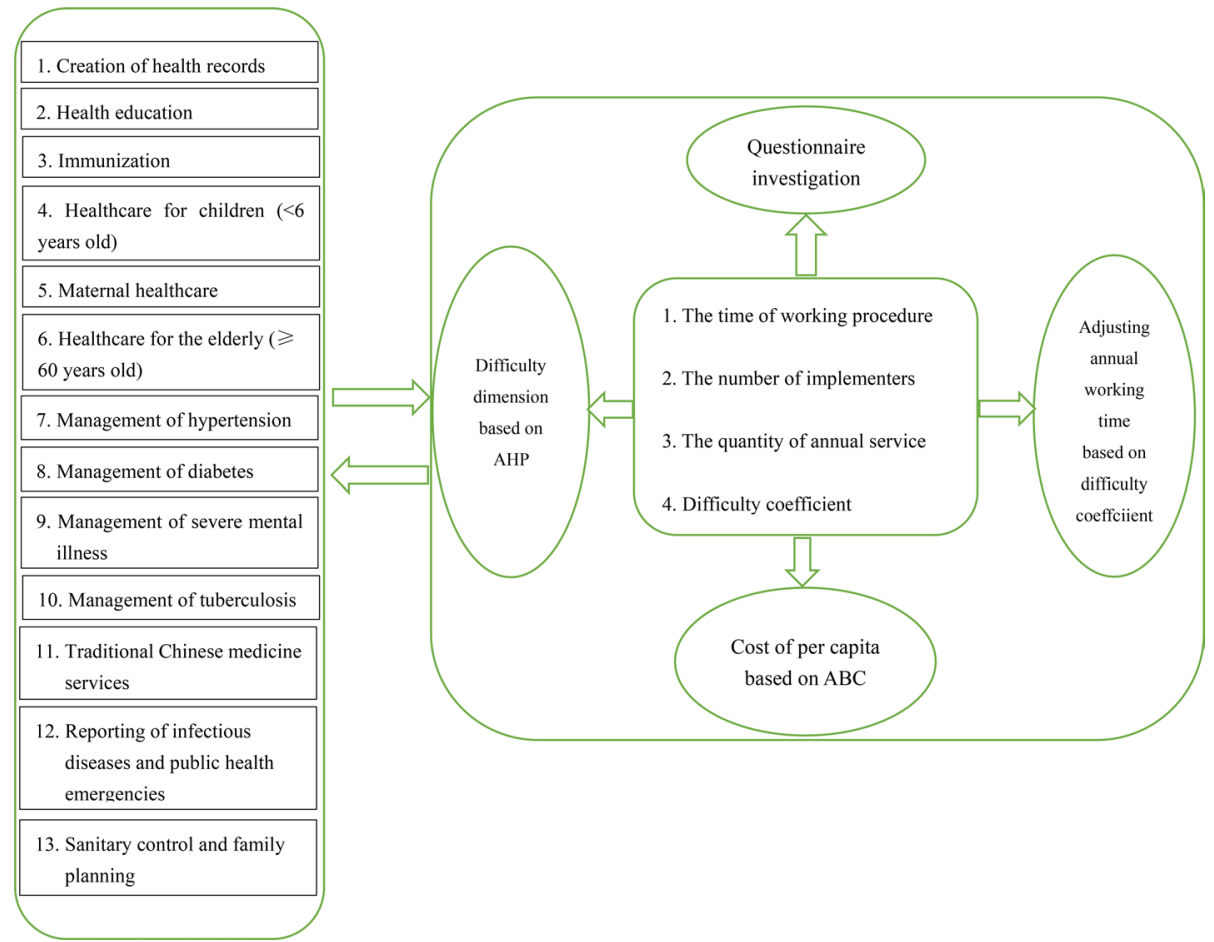

Figure 1 Key component of this study and the corresponding method. ABC, activity-based costing; AHP, analytical hierarchy process.

2. The data obtained from the website and health information system of Zhuhai:

The demographic data came from the Zhuhai Statistical Yearbook 2016 published online by the Zhuhai Statistical Bureau.

The annual service quantity data of BPHS came from the community health information system of Zhuhai.

\section{Scope of cost collection}

This study divided the cost of BPHS into three categories: human resource costs (HRC), medical consumables costs (MCC) and operating costs (OC).

HRC is calculated on the basis of the time consumed in BPHS. MCC includes the reagents and consumables used in providing BPHS. OC includes rent, charges for water, electricity and and the depreciation fees of fixed assets. After the total cost is determined, the proportion of the BPHS staff members is apportioned by the proportion of the entire staff of the 19 primary healthcare facilities. Human cost is the leading cost in BPHS.

\section{Questionnaire design}

We used an extensive literature review and interviews with PHF doctors as the basis to formulate three questionnaires to evaluate the cost of providing BPHS. The first questionnaire covers the basic situation, the allocation of human resources and the financial revenue and expenditure of the 19 primary healthcare facilities. The second questionnaire covers the annual service quantity of the service items, number of work hours and number of implementers. The third questionnaire is used to assess the difficulty coefficient in providing BPHS.
The first questionnaire was completed by 19 financial personnel, while the second and third questionnaires were completed by 114 employees engaged in BPHS. Face-to-face interviews were conducted using self-made questionnaires. When necessary, investigators provided assistance in filling out the questionnaires. The survey task in each PHF was completed in approximately 1 day.

\section{Cost estimation}

Human resource costs

Step 1: HRC per minute is calculated as follows:

$$
\text { HRC per minute }=\frac{\sum E}{\sum S} / 251 / 8 / 60 \text {, }
$$

where $E$ is the expenditure on personnel and $S$ is the number of staff members.

Note: The number of Chinese working days in 2016 was 251 days, and an 8 hour shift is in place.

Step 2: The actual working hours for each of the 13 service items are calculated as follows:

$$
T=t \times s,
$$

where $T$ is the actual working time for the 13 service items, $t$ is the actual working time for conducting one service item and $s$ is the actual number of staff members conducting one service item.

Step 3: HRC is calculated as follows:

$$
H R C=H R C \text { per minute } \times \sum T \text {. }
$$


Medical consumables costs

MCC is calculated as follows:

$M C C=\sum E 1+\sum E 2$,

where $E_{1}$ is the health material expenses incurred in BPHS and $E_{2}$ is the low-priced and easily worn articles used in BPHS.

Operating costs

$\mathrm{OC}$ is calculated as follows:

$$
O C=\frac{\sum(E 3+E 4)}{N} n
$$

where $E 3$ is the public service and daily operating expenses, $E 4$ is the depreciation for plant assets, $N$ is the total number of personnel and $n$ is the total number of employees engaged in BPHS.

\section{Cost of per capita of BPHS}

$$
\text { Cost of per capita of BPHS }=\frac{H R C+M C C+O C}{P},
$$

where $P$ is the size of the service population.

\section{Analytical hierarchy process}

Analytical hierarchy process (AHP) is a useful method for defining the weight of indicators on the basis of a mutual comparison judgement matrix by calculating the relative importance value. We used the yaahp V.10.0 software to obtain the normalised weight coefficient after calculating the initial weight. A consistency test was subsequently performed, and the matrix results can be analysed when consistency ratio $>0.10 .{ }^{20} \mathrm{AHP}$ can completely reveal the role of weight, particularly in determining the weight of the 13 service items of BPHS. Finally, four difficulty dimensions were determined: the coordination of residents, staff workload, complexity of work-related skills and basic qualities of staff members.

\section{Activity-based costing}

Activity-based costing (ABC) divides a service item into operating processes and calculates the cost of each operation process to determine the cost of all the service items. Hence, this approach is suitable for estimating the cost of BPHS. ABC calculates a service item's cost based on the resources utilised in each operating process, thereby avoiding the influence of the apportion coefficient error of cost estimation.

Defining the operating process is essential in this research. We referred to the National Standard of BPHS (Third Edition), consulted experts engaged in BPHS and visited Zhuhai for a pre-investigation. The operating process of BPHS involves 13 service items, 48 subitems, 95 secondary subitems and 308 operating processes.

\section{Statistical analysis}

A database was built using EpiData V.3.1, and double data entry was performed. SPSS 23.0 and Excel 2013 were used to perform descriptive statistical analyses of the arithmetic mean and constituent ratio.

\section{Patient and public involvement}

The patients and the public were not involved in our study.

\section{RESULTS}

\section{Basic situation}

In this study, 19 PHFs were surveyed; of these 13 PHFs are owned by the state, and six PHFs are privately owned, accounting for $68.43 \%$ and $31.57 \%$ of the PHFs, respectively. The 19 PHFs cover 924987 residents in Zhuhai. A total of 263 out of 1701 employees are engaged in BPHS, thereby accounting for $15.46 \%$. The average annual number of outpatients is 135840 . The average service radius is $7.92 \mathrm{~km}^{2}$, and the average business floor area is $4169.47 \mathrm{~m}^{2}$.

\section{Difficulty dimension and workload coefficient}

The difficulty coefficient is scored on the basis of the difficulty dimension after weighting, and the scores are added thereafter. $^{21}$ Difficulty dimensions are inherent attributes that reflect the actual operating difficulty of BPHS.

The research group summarised the four difficulty dimensions of BPHS obtained through the literature review and preliminary investigation in Zhuhai. The four difficulty dimensions are the coordination of residents, staff workload, complexity of work-related skills and basic qualities of staff. Some indicators were also included (see online supplementary file 1). An analytical hierarchy process was used to calculate the weights of the difficulty dimension on the basis of the results of the survey (third questionnaire), which involved 152 experts. The weights of the difficulty dimensions of BPHS in Zhuhai were as follows: $35.04 \%$ (coordination of residents), $24.03 \%$ (staff workload), $21.36 \%$ (complexity of work-related skills) and $19.59 \%$ (basic qualities of staff).

We obtained the difficulty coefficient of a subitem after determining the weight of each difficulty dimension and scoring the difficulty dimensions. We multiplied the weights and added the weighted scores of the four dimensions. Online supplementary file 1 shows that providing health education materials has the minimum difficulty coefficient (1.00), while immunological surveillance has the maximum difficulty coefficient (7.25) in 95 secondary subitems. We calculated the coefficient of the working time adjustment by dividing the difficulty coefficient of each secondary subitem by the average difficulty coefficient (5.28). Table 1 defines the index of the difficulty dimension.

\section{Annual working time}

The actual working time, number of working staff members who conducted one service item and the annual workload were investigated. Thereafter, these variables are multiplied and adjusted by the difficulty coefficient. We also calculated the total time of BPHS in Zhuhai (ie, 1090725 hours). The time spent for each of the 13 service items differs (see table 2). Immunisation 
Table 1 Definition of the indices of the difficulty dimension

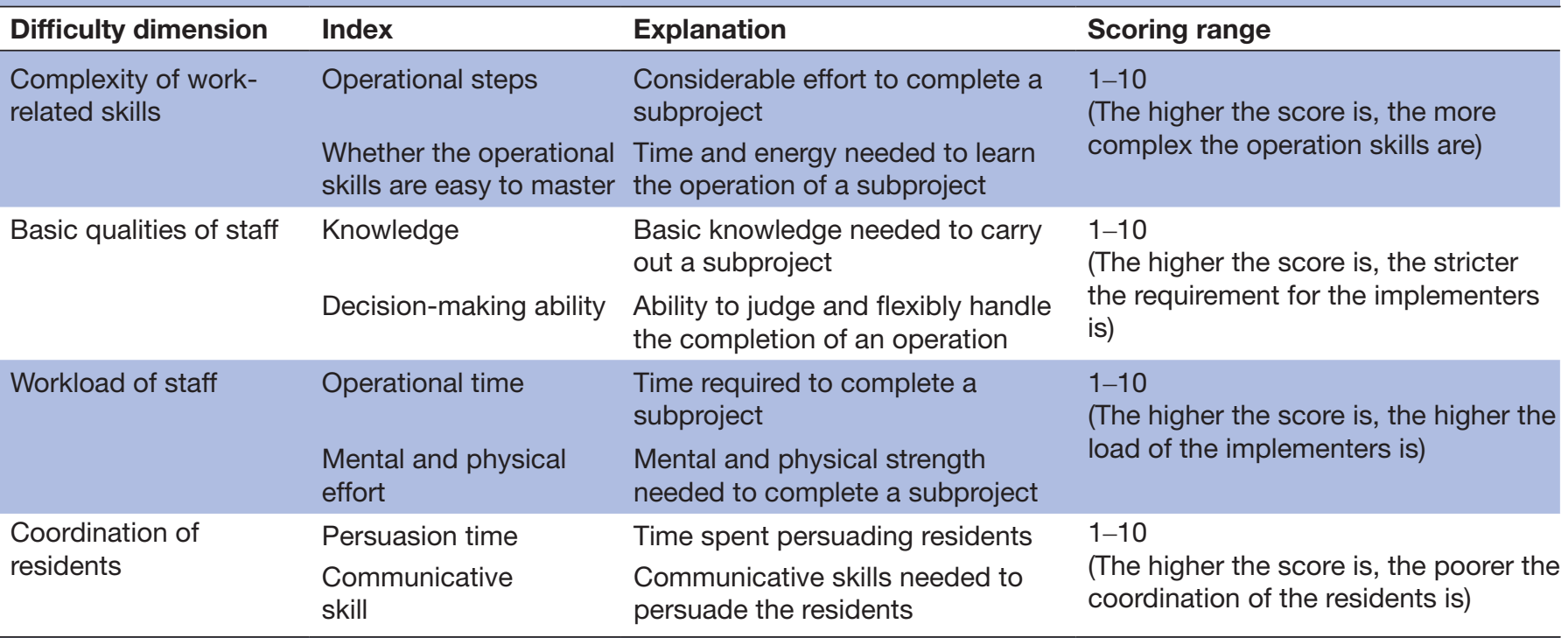

requires the longest working time (205 782 hours), while the management of tuberculosis requires the shortest working time (6205 hours).

\section{Per capita cost of each project of BPHS}

The cost of each service item per capita was calculated on the basis of the proportion of the annual working time of the 13 service items. We computed the per capita cost of each item by multiplying the actual cost per capita $(97.48$ RMB or 12.76 EUR) by the percentage of each item. Table 3 shows that immunisation was the costliest item
(17.82 RMB or 2.33 EUR per person), while the management of tuberculosis was the least costly item (0.57 RMB or 0.07 EUR per person).

\section{Total per capita cost of BPHS}

This study mainly aimed to calculate the per capita cost of BPHS. This cost was compensated in the majority of Chinese cities on the basis of the actual needs of the residents.

First, we calculated the human resource costs (HRC). In 2016, the expenditure for HRC in Zhuhai was

Table 2 Annual working time for each service item in the 2016 BPHS project

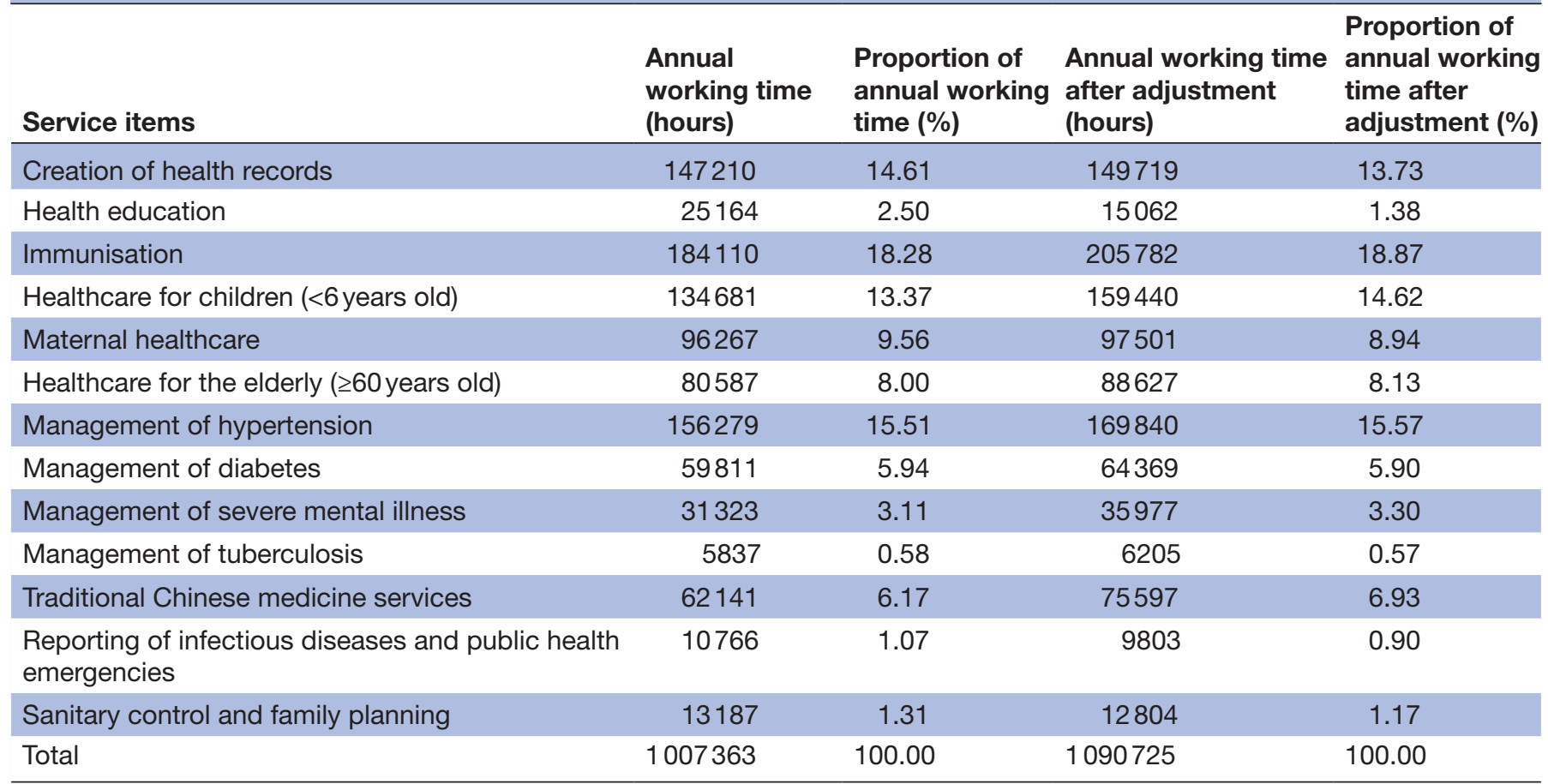

BPHS, basic public health service. 
Table 3 Per capita cost of each service item in the BPHS project

\begin{tabular}{|c|c|c|}
\hline Service items & $\begin{array}{l}\text { Proportion of } \\
\text { annual working } \\
\text { time (\%) }\end{array}$ & $\begin{array}{l}\text { Per capita cost of } \\
\text { each service item } \\
\text { RMB(EUR)/person }\end{array}$ \\
\hline $\begin{array}{l}\text { Creation of health } \\
\text { records }\end{array}$ & 14.61 & $14.24(1.86)$ \\
\hline Health education & 2.50 & $2.44(0.32)$ \\
\hline Immunisation & 18.28 & $17.82(2.33)$ \\
\hline $\begin{array}{l}\text { Healthcare for } \\
\text { children (<6 years } \\
\text { old) }\end{array}$ & 13.37 & $13.03(1.71)$ \\
\hline Maternal healthcare & 9.56 & $9.32(1.22)$ \\
\hline $\begin{array}{l}\text { Healthcare for the } \\
\text { elderly ( } \geq 60 \text { years old) }\end{array}$ & 8.00 & $7.80(1.02)$ \\
\hline $\begin{array}{l}\text { Management of } \\
\text { hypertension }\end{array}$ & 15.51 & $15.12(1.98)$ \\
\hline $\begin{array}{l}\text { Management of } \\
\text { diabetes }\end{array}$ & 5.94 & $5.79(0.76)$ \\
\hline $\begin{array}{l}\text { Management of } \\
\text { severe mental illness }\end{array}$ & 3.11 & $3.03(0.40)$ \\
\hline $\begin{array}{l}\text { Management of } \\
\text { tuberculosis }\end{array}$ & 0.58 & $0.57(0.07)$ \\
\hline $\begin{array}{l}\text { Traditional Chinese } \\
\text { medicine services }\end{array}$ & 6.17 & $6.01(0.79)$ \\
\hline $\begin{array}{l}\text { Reporting of } \\
\text { infectious diseases } \\
\text { and public health } \\
\text { emergencies }\end{array}$ & 1.07 & $1.04(0.14)$ \\
\hline $\begin{array}{l}\text { Sanitary control and } \\
\text { family planning }\end{array}$ & 1.31 & $1.28(0.17)$ \\
\hline Total & 100.00 & $97.48(12.76)$ \\
\hline
\end{tabular}

BPHS, basic public health service.

242.81 million RMB (31.79million EUR). The total number of employees in 19 PHFs was 1701 . The number of working days in 2016 was 251 days, while the working time per day was 8 hour based on the national standard. Thus, the HRC per minute of BPHS in Zhuhai is 1.18 RMB (0.15 EUR). The actual working time of BPHS in 2016 was $65443494 \mathrm{~min}$. Therefore, the HRC of BPHS in Zhuhai is 77.54 million RMB (10.15 million EUR).

Second, we calculated the medical consumables costs (MCC). In 2016, 19 PHC facilities in Zhuhai spent 3.78 million RMB (0.49 million EUR) on health materials used in BPHS, while 629189 RMB (82 651 EUR) was spent for low priced and easily worn out articles. Therefore, the MCC of BPHS in Zhuhai was 4.42 million RMB (0.75 million EUR).

Third, we calculated the operating costs (OC). In 2016, the total daily operating expenses was 46.28 million RMB (6.06 million EUR), while the depreciation for plant assets was 6.88 million RMB ( 0.9 million EUR). The total number of employees in 19 PHFs was 1701, while the number of staff members engaged in BPHS was 263.
Thus, the OC of BPHS in Zhuhai was 8.22 million RMB (1.08 million EUR).

After calculating HRC, MCC and OC, we found that the size of the service population in PHF in Zhuhai was 924 987. Finally, the total cost per capita of the BPHS project in Zhuhai was 97.48 RMB (12.76 EUR).

\section{DISCUSSION \\ Cost reimbursement standard}

The compensation standard in the BPHS project in Zhuhai in 2016 was 55 RMB (7.2 EUR) per person. However, our calculation showed that the actual cost per capita is 97.48 RMB (12.76 EUR). Thus, the compensation was reduced by 42.48 RMB (5.55 EUR). In 2015, the subsidy standard in Beijing reached 87.97 RMB (11.55 EUR), ${ }^{22}$ whereas in Shanghai it was 59.62 RMB (7.80 EUR). ${ }^{23}$ Shenzhen had the highest compensation standard in China at 95 RMB (12.44 EUR) in $2016 .{ }^{24}$ The current trend indicates that the compensation for HRC, MCC and OC will increase annually. The government should improve the compensation standard to reimburse the actual cost incurred by PHFs in providing BPHS. HRC is the principal cost in providing BPHS. In Zhuhai, HRC accounts for $60.46 \%$ of the total costs, whereas that in Guangzhou and Shenzhen accounts for $72 \%$ and $70.2 \%$, respectively. ${ }^{25} 26$ Accordingly, local governments should establish a mechanism to increase the standard salary of personnel engaged in PHF to compensate for HRC. Additionally, the OC of PHFs that pay rent is higher than that of those not paying rent, thereby increasing the operating pressure in providing BPHS. Hence, the government should provide subsidies to PHFs that pay rent to boost their enthusiasm for providing BPHS.

\section{Priority projects of BPHS}

BPHS has an irreplaceable role in promoting the health status of Chinese residents and in realising equitable access to basic healthcare. Given the limited funding for BPHS, funds should be allocated to the priority service items that have a high difficulty coefficient and require a heavy workload. These items include immunisation, healthcare for children below 6years old, maternal healthcare and the management of non-communicable chronic diseases. These services can effectively improve the health status of vulnerable groups. The government should prioritise these items by increasing subsidy standards to boost the enthusiasm of medical staff. Health education has the lowest difficulty coefficient, while community health education affects residents' health literacy, thereby substantially influencing residents' participation in BPHS. ${ }^{27}$ Therefore, investment in health education cannot be reduced in BPHS.

\section{Performance evaluation of BPHS}

Currently, the allocation of BPHS funds in China is linked to the performance appraisal of PHFs; this appraisal is conducted by the health bureau, with quantity, quality and 
satisfaction of the residents as the basis of the appraisal. ${ }^{28}$ Zhuhai has established a relatively reasonable performance management system. That is, all PHFs must satisfy a required level of performance to receive sufficient funds for BPHS. However, the government should also set the incentive standard to encourage PHFs to render the service items. Performance-based rewards are awarded on the basis of the workload of employees in providing BPHS, and this approach gradually eliminates equalitarianism. ${ }^{29}$ PHF should demand that staff members who do not engage in BPHS actively participate in BPHS to guarantee the completion of their tasks.

\section{Public financing of BPHS}

The development of BPHS requires financial support from local governments. The Chinese government is currently facing two major problems in allocating funding for healthcare. First, the burden of local government is relatively heavy. In 2016, the central government compensated a mere 8.5 RMB (1.11 EUR) for BPHS in Zhuhai. The remainder was subsidised by the local government. If the actual cost per capita is 97.48 RMB (12.76 EUR), as shown in our calculation, then the Zhuhai local government will undoubtedly face immense pressure. According to a WHO report in 2017, global health expenditures account for $11.7 \%$ of total government expenditures. ${ }^{30}$ The Chinese government spends only $7 \%$ of its total expenditure on healthcare, ${ }^{31}$ which has not reached the average level. Hence, the central government should increase the proportion of expenditures spent on healthcare and assume additional responsibility in cost reimbursement in BPHS. ${ }^{32}$

Second, financial channels are lacking. Particularly, the allocation of budgets for healthcare by the Chinese government mainly depends on the national budget, thereby resulting in a failure to meet the capital needs for the development of the BPHS projects. ${ }^{33}$ The WHO Financing Conference recommends increasing the tax for air tickets, foreign exchange transactions, mobile communications, cigarettes and alcohol to raise over US\$ 10 billion annually, which can be channelled to the global healthcare system. ${ }^{34}$ Therefore, China should maximise the diversified financing channels to expand its financial capability to alleviate the lack of funds for BPHS.

\section{Improving the efficiency of BPHS}

Relevant studies have shown that increasing the subsidy of BPHS contributes to improving the efficiency of PHFs. ${ }^{35}$ Specifically, PHFs no longer need to spend their own funds for BPHS after the government has provided sufficient subsidies, thereby reducing their operational burden. The increased government subsidies for BPHS, particularly for services with heavy workloads, were conducive to mobilising the enthusiasm and improving the work efficiency of staff members. ${ }^{36}$ Moreover, 263 staff members of 19 PHFs are engaged in BPHS, thereby accounting for only $15.46 \%$ of the total number of staff members. According to the standards issued by the
Ministry of Health, 0.87 staff members engaged in BPHS are required for every 1000 residents. ${ }^{37}$ Hence, 804 staff members are actually required in the areas covered by 19 PHFs. Accordingly, the government should allocate personnel on the basis of the proportion of the actual needs to improve service efficiency and reduce the workload of employees. The informatisation of PHFs is also the main approach to improving service efficiency. ${ }^{38}$ This approach can develop a family doctor service app, thereby enabling online appointments and communication and improving the efficiency of BPHS provided by family doctors. ${ }^{39}$

\section{Exploring the method of cost estimation}

TDABC and equivalent methods have their own advantages and disadvantages in estimating the cost of BPHS. ${ }^{17}$ TDABC allocates the cost of related resources to the project or activity based on the actual contribution, which is evident when some indirect costs (eg, management costs) account for a large proportion of the total cost. $\mathrm{ABC}$ is a bottom-up calculation method that facilitates the tracking of staff contributions to projects or activities. The more specified the operating process of BPHS cost is and the more precise the self-reporting, the more accurate the cost estimation will be. ${ }^{40}$ The concept of 'standard service equivalent' was introduced into the study of the Beijing area. This concept converted the working hours of BPHS into equivalent values, thereby enabling the direct addition and comparison of the workload of each service project. ${ }^{22}$ The disadvantage is that only the human cost was considered when calculating the cost of the 'standard service equivalent'. Other costs, such as material costs and public funds, are disregarded, thereby affecting the accuracy of the cost estimation. This disregard is also the reason that this study adopts TDABC to calculate the cost.

\section{Limitations}

This study has some limitations. In particular, this study is a cross-sectional study performed in Zhuhai only. Thus, the generalisability of the cost estimation method of BPHS should be validated. Additionally, this research can only reflect the situation in 2016. We should likewise accumulate a considerable amount of data on BPHS to build a cost prediction model. Finally, although 13 CHCs with large service populations were selected as survey sites, which provided a good representation of the delivery of BPHS in Zhuhai, there are potential biases in the results due to excluding smaller CHCs.

\section{CONCLUSION}

BPHS in Zhuhai receives inadequate financial subsidies and requires considerable working time, while a heavy workload is assigned to the engaged personnel. The subsidy should be increased on the basis of the actual per capita cost, and funds should be channelled to priority projects to ensure the reasonable use of capital resources. 
The existing performance incentives should be improved, and the government should increase its budget allocation for BPHS.

Acknowledgements We thank all the investigators who took part in the data collection. We also express our gratitude for the support of the Zhuhai Health Bureau and the Prevention and Treatment Centre of Chronic Disease.

Contributors JL and ZL designed the study. ZW, QA and YL collected data and conducted the data analysis. ZW drafted the paper. JL and $Q W$ revised the manuscript. All the authors read and approved the final manuscript. JL is the guarantor of the paper.

Funding The study was funded by the Zhuhai Health and Family Planning Bureau. Competing interests None declared.

Patient consent for publication Not required.

Ethics approval The study was approved by the Ethics Committee of Tongji Medical College, Huazhong University of Science and Technology (No. 201412). The Zhuhai Health Bureau approved the investigation. Informed consent was obtained from all the participants.

Provenance and peer review Not commissioned; externally peer reviewed.

Data sharing statement № additional data are available.

Open access This is an open access article distributed in accordance with the Creative Commons Attribution Non Commercial (CC BY-NC 4.0) license, which permits others to distribute, remix, adapt, build upon this work non-commercially, and license their derivative works on different terms, provided the original work is properly cited, appropriate credit is given, any changes made indicated, and the use is non-commercial. See: http://creativecommons.org/licenses/by-nc/4.0/.

\section{REFERENCES}

1. Zhang $Y$, Chen M, Shi XQ. Challenges of basic public health services provided by village doctors in Guizhou, China. Asia Pac J Public Health 2015;27:69S-76.

2. Makumbi I. Investing in health: world development report 1993 (WDR). Forum for Development Studies 1994;20:114-7.

3. Office USGA. GAO Cost Estimating and Assessment Guide: Best Practices for Developing and Managing Capital Program Costs (Supersedes GAO-07-1134SP). 2009:1.

4. Resnick BA, Fisher JS, Colrick IP, et al. The Foundational Public Health Services as a Framework for Estimating Spending. Am J Prev Med 2017;53:646-51.

5. Leider JP, Resnick B, Sensenig AL, et al. Assessing the Public Health Activity Estimate from the National Health Expenditure Accounts: Why Public Health Expenditure Definitions Matter. J Health Care Finance 2016;42.

6. Mays GP, Brian C. Estimating the Costs of Foundational Capabilities for the Nation's Public Health System. University of Kentucky Center for Public Health Systems and Services Research Working Paper Series, 2016.

7. Kaplan RS, Anderson SR. Time-driven activity-based costing. MA: Harvard Business School Press, 2007:131-8.

8. Mandigo M, O'Neill K, Mistry B, et al. A time-driven activity-based costing model to improve health-care resource use in Mirebalais, Haiti. Lancet 2015;385:S22.

9. Chen Z. Launch of the health-care reform plan in China. Lancet 2009;373:1322-4.

10. Yip WC, Hsiao WC, Chen W, et al. Early appraisal of China's huge and complex health-care reforms. Lancet 2012;379:833-42.

11. National Health and Family planning commission. Notice concerning the preparation of the national basic public health service project in 2017. 2017. Available at http://www.nhfpc.gov.cn/jws/s3577/201709/ fb16b2e306bd469ab84e0c42173bc52d.shtml (accessed 7 Apr 2018).

12. Ministry of Health. Notice of the ministry of health on the issuance of the national basic public health service specification (2009 edition). 2009. Available at http://www.moh.gov.cn/jws/s3581r/200910/fe1c dd87dcfa4622abca696c712d77e8.shtml (accessed 7 Apr 2018).

13. Ministry of Health. Notice of the ministry of health on the issuance of the national basic public health service specification (2011 edition). 2011. Available at http://www.nhfpc.gov.cn/jws/s3577/201105/ 51780.shtml (accessed 7 Apr 2018).

14. National Health and Family planning commission. Notice concerning the implementation of the national basic public health service project in 2016. 2016. Available at http://www.nhfpc.gov.cn/jws/s3577/ 201606/f29a4659c7f4455ca6f62f8d14eb4b02.shtml (accessed 7 Apr 2018).

15. Xia HH. Study on cost estimation and compensation mechanism of community public health services in Guangzhou [D]: Huazhong University of Science and Technology, 2009.

16. Bp M. The Research on Cost of Community Basic Public Health Services in Guangzhou and Shenzhen [D]: Guangdong Pharmaceutical University, 2014.

17. Wang Z, Ao Q, Liu JA, et al. Research progress of cost estimation of community basic public health service in China. Chinese Journal Of Health Policy 2017;10:42-8.

18. Yin DL, Cheng BW, Cheng W, et al. Constructing the Cost Estimation Model for Community Health Service Items in Beijing [J]. Chinese Health Economics 2015;34:42-4.

19. Zhuhai statistics bureau. Overview of Zhuhai in 2016. 2016. Available at http://www.stats-zh.gov.cn/zhgl/201605/P020170317610514 080431 (accessed 7 Apr 2018).

20. Cheng EWL, Li H. Analytic hierarchy process. Measuring Business Excellence 2001:5:30-7.

21. Yan A, Linghong L I, Business SO, et al. Exploratory Research on Difficulty Coefficient Application in Performance Evaluation Field. Science \& Technology Management Research 2014.

22. Yin D, Wong ST, Chen W, et al. A model to estimate the cost of the National Essential Public Health Services Package in Beijing, China. BMC Health Serv Res 2015;15:222.

23. Zhao XC, Zhang X, Chen PP, et al. Study on the Activity-Based Costing Management (ABC/M) for the primary health service project costs in pudong New Area,Shanghai. $J$ of Pub Health and Prev Med 2015;26:58-60.

24. Hou WL, Zhao ZG, Xia TS, et al. The budget prediction of basic public health service in the community. Chinese Journal of General Practice 2016;14:879-82.

25. Xia HH, et al. Study on Cost Estimation of Community Health Services in Guangzhou. Medicine and Society 2010;23:51-4.

26. Cheng YQ, Jiang HP, Luo LX, et al. Study on human resource cost of the running of community public health service package in Shenzhen. Chinese Hospital Management 2010;30:13-15.

27. Park SE, Donoff RB, Saldana F. The Impact of Integrating Oral Health Education into a Medical Curriculum. Med Princ Pract 2017;26:61-5.

28. Zhao Y, Cui S, Yang J, et al. Basic public health services delivered in an urban community: a qualitative study. Public Health 2011;125:37-45.

29. Liu X, Tan A, Towne SD, et al. Awareness of the role of general practitioners in primary care among outpatient populations: evidence from a cross-sectional survey of tertiary hospitals in China. BMJ Open 2018;8:e020605.

30. Organization W H. World health statistics 2017. Monitoring health for the SDGs Sustainable Development Goals. Geneva Switzerland: WHO, 2017:293-328.

31. National Health and Family planning commission. China health statistics yearbook in 2017. Beijing, China: China union medical university press, 2017.

32. Deng F, Lv JH, Wang HL, et al. Expanding public health in China: an empirical analysis of healthcare inputs and outputs. Public Health 2017;142:73-

33. Zhu K, Zhang L, Yuan S, et al. Health financing and integration of urban and rural residents' basic medical insurance systems in China. Int J Equity Health 2017;16:194.

34. Organization $\mathrm{W} \mathrm{H}$. "Health systems financing:the path to universal coverage" focuses on 10 opportunities to improve efficiencies. The world health report 2013;2010.

35. Gui-Lin Z, Xi-Long P. Evaluating the efficiency of basic public health service project in Beijing rural areas based on data envelopment analysis[J]. J Peking Univ 2013;45:264-8.

36. Li T, Lei T, Xie Z, et al. Determinants of basic public health services provision by village doctors in China: using non-communicable diseases management as an example. BMC Health Serv Res 2016;16:42

37. Ding Y, Smith HJ, Fei Y, et al. Factors influencing the provision of public health services by village doctors in Hubei and Jiangxi provinces, China. Bull World Health Organ 2013;91:64-9.

38. Lai M, Fan ZJ, Zhang LL. The development, current state, and effects of community informatization in mainland China. Libr Trends 2013;62:13-33.

39. Lihong Z, Lu L, Yiming Z. UK electronic health records development and its implications to China. Journal of Information Resources Management 2014;4:94-100.

40. Kaplan RS, Anderson SR. Time-driven activity-based costing. Social Science Electronic Publishing 2007;19:343-6. 